\title{
O uso da fotografia na pesquisa em Psicologia ${ }^{1}$
}

\author{
Lucas Neiva-Silva \\ Sílvia Helena Koller \\ Universidade Federal do Rio Grande do Sul
}

\begin{abstract}
Resumo
A fotografia vem sendo amplamente utilizada na pesquisa em Psicologia, em diferentes áreas, para investigação das mais diversas questões. Contudo, este recurso ainda é pouco utilizado no Brasil. O objetivo deste trabalho é realizar, com base na literatura científica, um levantamento histórico-metodológico do uso da fotografia na ciência psicológica. Foram identificadas quatro funções principais da fotografia nos diferentes métodos adotados: registro, modelo, feedback e autofotografia. Em cada uma destas funções, são apresentados diversos estudos realizados, destacando suas vantagens e desvantagens. Paralelamente, procurou-se levantar os temas abordados nas variadas áreas da Psicologia, através do recurso fotográfico. Por fim, enfatizouse a descrição do método autofotográfico, no qual são destacadas especificidades e possíveis contribuições obtidas pela sua utilização.
\end{abstract}

Palavras-chave: Fotografia, Autofotografia, Método autofotográfico, Método de pesquisa.

\begin{abstract}
The use of photography in psychological research.

Photography has been used widely in different areas of psychological research, in the investigation of several subjects. However, this resource is still little used in Brazil. The objective of this work is, based on the scientific literature, to describe the historical-methodological use of photography in psychological science. Four main functions of its use are identified: recording, model, feedback, and the auto-photographic function. Several studies are presented, highlighting the advantages and disadvantages of each function. We attempt to bring out different themes of psychological study, using photography as a resource. Finally, a description of the auto-photographic method is detailed, outlining its specificities and potential uses.

Key words: Photography, Auto-photography, Auto-photographic method, Research method.
\end{abstract}

A pesquisa em Psicologia vem sendo fortemente favorecida pelo desenvolvimento da tecnologia em diferentes setores. Recursos computacionais, que há algumas décadas eram exclusivos de grandes empresas, hoje fazem parte dos instrumentos básicos da grande maioria dos pesquisadores. Observa-se que o uso da informática tornase cada vez mais presente, tanto na coleta e na análise dos dados, como na apresentação final dos resultados. De forma semelhante, a utilização de câmeras de vídeo na gravação de imagens se tornou um grande instrumento de coleta de dados. Em virtude da melhoria da qualidade da imagem e do som, somada à facilidade de manuseio e à diminuição de custos, estes equipamentos são, hoje, utilizados em inúmeras pesquisas, nas mais diferentes áreas da Psicologia. Verificase, contudo, que, comparativamente, não se tem muitos registros, no Brasil, do uso da fotografia na pesquisa psicológica.
A fotografia foi desenvolvida antes das câmeras de vídeo e dos computadores e vem contribuindo para a construção do conhecimento científico em Psicologia há mais de cem anos. O objetivo deste trabalho é realizar, com base na literatura científica, um levantamento histórico-metodológico do uso da fotografia na pesquisa psicológica. Procurou-se identificar as funções gerais ocupadas pela fotografia nos diferentes métodos adotados, ressaltando as vantagens e desvantagens em cada um deles. Paralelamente, buscou-se levantar os diferentes temas abordados nas diversas áreas da ciência psicológica, através do recurso fotográfico.

O principal objetivo, ao se trabalhar com a fotografia junto à Psicologia, atualmente, é a atribuição de significado à imagem. As relações estabelecidas entre estes dois construtos foram, inicialmente, colocadas por William James (1890, citado por Dinklage \& Ziller, 1989) que definiu o significado das palavras como sendo imagens sensoriais trazidas à consci- 
ência. Assim, adotando-se o pressuposto de que parte das pessoas teria dificuldade em expressar verbalmente determinados temas, o uso da fotografia poderia auxiliar na comunicação destes significados, permitindo uma melhor compreensão destes conteúdos por parte do pesquisador.

Analisando a literatura a respeito do uso da fotografia na pesquisa psicológica, é possível identificar quatro funções principais no uso do recurso fotográfico. A primeira delas é a função de registro, na qual a fotografia tem o papel de documentar determinada ocorrência, ou seja, a mesma função que as filmagens possuem nos dias de hoje. Fotografa-se um certo evento durante o seu acontecimento e, posteriormente, esta imagem é tomada como um dado de pesquisa na análise específica do "motivo fotográfico", isto é, da ação, pessoa ou objeto fotografados. Neste caso, o que importa é apenas o conteúdo presente em cada uma das fotos ou no conjunto delas. Por esta razão, não são levados em consideração o autor das fotografias, nem o posterior observador das mesmas, que, em ambos os casos, tende a ser o próprio pesquisador ou alguém da sua equipe de trabalho.

No segundo caso, a fotografia desempenha a função de modelo. São apresentadas aos participantes, fotos que enfocam determinado tema, normalmente relacionado com o objeto de estudo, mas que não retratam os próprios participantes. São então analisadas as percepções, falas ou reações das pessoas em relação às imagens. $\mathrm{O}$ foco principal de análise passa a ser o observador da fotografia, juntamente com as suas respostas direcionadas às diferentes fotos apresentadas. $\mathrm{O}$ conteúdo da imagem, com freqüência, ocupa o lugar de variável independente, sendo modificado no intuito de se observar alguma possível variação nos comportamentos ou percepções dos participantes. Nestas pesquisas, não é importante considerar quem é o autor das fotos, pois, na maioria dos casos, isto pouco mudaria a opinião da pessoa em relação à imagem em si.

A terceira função da fotografia na pesquisa é denominada autofotográfica. Nestes estudos, cada participante recebe uma câmera fotográfica e é instruído sobre como manuseá-la adequadamente. Posteriormente, é solicitado a tirar determinado número de fotos na tentativa de responder a uma questão específica. Após a revelação do filme, é analisado o conteúdo das fotos. Em parte das pesquisas, são também desenvolvidas entrevistas com os participantes com o intuito de se levantar as percepções a respeito das suas próprias fotografias. Observam-se diferenças significativas em relação às duas funções anteriores, pois, neste caso, são considerados importantes tanto o conteúdo, quanto o autor das fotos, assim como a sua percepção em relação às próprias imagens produzidas.

Em relação ao conteúdo das fotografias, como será explicitado posteriormente, a literatura (Amerikaner, Schauble \& Ziller, 1980; Clancy \& Dollinger, 1993; Combs \& Ziller, 1977; Dinklage \& Ziller, 1989; Dollinger, 1996; Dollinger, 2001; Dollinger, no prelo; Dollinger \& Clancy, 1993; Dollinger, Cook \& Robinson, 1999; Dollinger \& Dollinger, 1997; Dollinger, Preston, O’Brien \& DiLalla, 1996; Dollinger, Rhodes \&
Corcoran, 1993; Dollinger, Robinson \& Ross, 1999; Dollinger, Ross \& Preston, no prelo; Henry \& Solano, 1983; Monteiro \& Dollinger, 1996, 1998; Okura, Ziller \& Osawa, 1985-86; Rorer \& Ziller, 1982; Ziller, 1990; Ziller \& Lewis, 1981; Ziller \& Rorer, 1985; Ziller \& Smith, 1977; Ziller, Vern \& de Santoya, 1988) indica o uso da técnica de análise de conteúdo, na qual são definidas categorias a partir dos diferentes assuntos presentes nas imagens. As freqüências de ocorrência de cada uma destas categorias são quantificadas e comparadas entre os diferentes grupos de participantes da pesquisa. A consideração dos autores das fotos é importante na medida em que os dados serão analisados de acordo com as características de cada autor ou em relação ao grupo ao qual ele pertence. Nas pesquisas com grupos contrastantes, por exemplo, é observado se determinado conjunto de fotos possui fatores peculiares a um grupo ou a outro.

A percepção dos autores a respeito de suas próprias fotos pode ser apreendida de diferentes maneiras. Pode-se pedir aos participantes que escolham as imagens percebidas como mais importantes; que estabeleçam uma ordem a partir das fotos que sejam consideradas mais significativas; ou que escrevam uma legenda para cada foto ou um parágrafo sobre o conjunto delas. Pode-se ainda realizar entrevistas, alcançando com maior profundidade a percepção dos participantes a respeito das fotografias.

$\mathrm{Na}$ quarta função, a fotografia é usada como um instrumento de feedback aos participantes da pesquisa. Na maioria destes casos, as pessoas são anteriormente avaliadas em determinado aspecto, como por exemplo, em algum traço de personalidade. Elas são, então, fotografadas por terceiros em diferentes circunstâncias e o resultado - as fotos - é apresentado às mesmas. Posteriormente é realizada nova avaliação com o intuito de verificar se o contato com as fotografias gerou alguma diferença no critério avaliado.

Diferentemente do método autofotográfico, a fotografia como feedback não se preocupa com o autor da foto, mas apenas com o resultado que esta gera sobre o participante. Esta função também se diferencia da fotografia como modelo, uma vez que neste último caso a imagem enfoca qualquer ação, pessoa, objeto ou símbolo e, no caso do feedback, o foco central é o próprio participante da pesquisa. Analisando-se a literatura, é possível observar que a fotografia na função de instrumento de feedback não se desenvolveu tanto quanto nos três primeiros casos. Isto se deu, principalmente, em virtude das limitações apresentadas pelo método em relação à restrição de possíveis temas a serem estudados através deste processo.

$\mathrm{O}$ primeiro artigo publicado de que se tem registro usando a fotografia na pesquisa psicológica data da última década do século XIX (Donaldson, 1890). Este período coincide, tanto com o início do desenvolvimento da Psicologia como ciência reconhecida, como também com o desenvolvimento da própria fotografia, que começava a se destacar naquele século. Tal pesquisa utilizou o recurso fotográfico na função de registro e tinha por objetivo encontrar relações entre o construto "inteligência" e estruturas anatômicas do cérebro 
de uma mulher surda-muda e cega, já falecida. Os resultados foram discutidos tomando por base diferentes critérios, como notas biográficas, dados físicos, fotografias do cadáver da mulher durante a autópsia, peso e volume encefálico. Apesar da fotografia não ter sido o principal instrumento de apreensão dos dados, mas apenas mais uma forma de registro dos dados em meio a diversas outras, este trabalho foi um marco da utilização deste recurso dentro da pesquisa psicológica.

Na primeira década do século XX, em um único ano foi publicada uma série de cinco trabalhos nos quais a fotografia, ainda na função de registro, era usada como principal forma de coleta de dados. O primeiro deles (Judd, Mcallister, Cloyd \& Steele, 1905) mostrava como o desenvolvimento de um novo equipamento especial denominado kinetoscope camera era usado em estudos sobre a movimentação ocular. McAlister (1905) estudou como os olhos se comportavam quando o participante era solicitado a, conscientemente, fixar o olhar em um ponto e como os olhos se moviam de um ponto de fixação para outro. Os demais trabalhos analisaram a percepção visual, quando os participantes observavam imagens que geravam ilusões óticas (Cameron \& Steele, 1905; Judd, 1905; Judd \& Courten, 1905). Nestas pesquisas, o recurso fotográfico foi utilizado, gerando, na época, grandes avanços dos estudos na área da percepção visual.

Na década de 20, a fotografia passou então a ser usada na pesquisa psicológica, adotando a função de modelo. Em um contexto no qual os países viviam as mudanças geradas pelo fim da Primeira Guerra Mundial, dentro da área de Recursos Humanos existia a necessidade de criar uma forma de seleção de pessoal que pudesse lidar com grande número de pessoas e que fosse, ao mesmo tempo, rápida e eficaz. A partir desta necessidade, foi desenvolvida uma pesquisa (Anderson, 1921) com o objetivo principal de determinar a confiabilidade da análise da fotografia do rosto de uma pessoa como indicador do nível de inteligência desta. Foi elaborado, como modelo, um catálogo com 69 fotografias de pessoas que ocupavam diferentes cargos em uma empresa. Cada imagem era identificada por um número. Estas pessoas participaram da validação de testes de inteligência nas Forças Armadas, e seus escores, neste teste, foram usados como critério de comparação. Coube a um corpo de 12 participantes, composto de estudantes e instrutores em Psicologia, analisar as fotos e escolher aquelas pessoas que melhor se enquadravam em quatro categorias: primeira, as sete pessoas mais inteligentes; segunda, as sete pessoas menos inteligentes; terceira, as 14 pessoas consideradas superiores, mas que não fossem tão inteligentes quanto as sete melhores; quarta, as 14 pessoas consideradas inferiores, mas não tão pouco inteligentes quanto as sete piores. Os dados mostraram que houve alta concordância entre o julgamento a partir da imagem e os escores de inteligência apenas em um caso: quando os graus extremo inferior e extremo superior de inteligência eram considerados. Entretanto, quando considerados os grupos "superiores médios" e "inferiores médios", não foram observadas correlações significativas entre julgamento a partir das imagens e os escores do teste de inteligência. Anderson
(1921), sabiamente, concluiu que, de uma forma geral, eleger empregados apenas pela análise da fotografia não é um método de seleção confiável.

O primeiro pesquisador que investigou a avaliação da inteligência através da fotografia foi Pintner (1918, citado em Laird \& Remmers, 1924). Em seu estudo, foram usadas fotografias de 12 crianças, com idades entre cinco e 12 anos, cujos níveis de inteligência haviam sido avaliados através do teste C.M.A. (sigla não explicitada pelo autor). Foram organizados vários grupos de juízes, dentre eles, médicos, psicólogos, estudantes, professores e um grupo formado por diferentes profissionais. Os juízes deveriam observar as fotos e organizá-las em uma seqüência, segundo o julgamento de qual criança teria maior ou menor nível de inteligência. Os níveis de correlação entre a sequiência estimada e a real variaram de $-0,63$ a $+0,52$. Surpreendentemente, a mais alta correlação foi obtida por um taquígrafo e o menor, por um psicólogo. Pintner concluiu que, "de uma forma geral, podemos dizer que é impossível, pelo significado das fotografias, ordenar crianças de acordo com sua inteligência" (1918, p. 293, citado em Gaskill, Fenton \& Porter, 1927, p. 399).

Por mais que, atualmente, pareça cômico o objeto de estudo destas pesquisas, na época, fazia referência a questões de suma importância, discutidas amplamente, tanto no meio acadêmico, quanto na área de seleção de pessoal. Diversos trabalhos foram realizados (Anderson, 1921; Gaskill, Fenton \& Porter, 1927; Laird \& Remmers, 1924; Uhrbrock, 1922, citado em Cook, 1939) avaliando a possibilidade de se estimar a inteligência de uma pessoa através da análise de sua fotografia, fato este aceito em grandes empresas norte-americanas, quando a análise era feita por experts em seleção de pessoal. A validade do julgamento da inteligência baseada em fotografias foi comparada com o julgamento da inteligência baseado em entrevistas (Moriwaki, 1929). Este autor concluiu que o julgamento baseado em entrevistas era nitidamente melhor que aquele baseado unicamente nas fotografias dos participantes.

Tentando pôr fim à questão do julgamento da inteligência a partir de fotografias, que se tornava mais relevante com o início da Segunda Guerra Mundial e a conseqüente necessidade de seleção de milhares de pessoas, Cook (1939) compôs um corpo de dez juízes formados por profissionais altamente capacitados na área de gerência de pessoal de diferentes grandes companhias norte-americanas, que analisou um total de 150 fotos. A inteligência das pessoas fotografadas foi determinada anteriormente pelo Teste de Inteligência de Thurstone IV. Concluiu-se que "todos os juízes estimaram a inteligência com aproximadamente o mesmo nível de inexatidão" (Cook, pp. 388-389), com índices de correlação variando entre $-0,6$ e +0,20. De forma semelhante, não houve precisão no que diz respeito aos níveis extremos ou medianos de inteligência. Laird e Remmers (1924) afirmaram em seu trabalho que os juízes, na tentativa de identificar quem eram as pessoas mais inteligentes através das fotos, "poderiam fazê-lo tão bem com os olhos fechados, quanto com os olhos abertos" (p. 445). 
Os resultados de todos estes trabalhos (Anderson, 1921; Cook, 1939; Gaskill, Fenton \& Porter, 1927; Laird \& Remmers, 1924; Moriwaki, 1929; Pintner,1918, citado em Laird \& Remmers, 1924; Uhrbrock, 1922, citado em Cook, 1939) influenciaram também o campo da educação, no qual o professor detinha grande poder, inclusive o de afirmar que um aluno era mais inteligente que outro apenas olhando para ambos. As conclusões obtidas pelos diferentes autores, tidas como óbvias pela ciência psicológica atual, apontaram, na época, para a necessidade de se aprimorar os testes de inteligência e de se criar novas técnicas de seleção de pessoal.

O recurso fotográfico vem sendo fortemente utilizado em diversas pesquisas sobre expressões faciais e comportamentais (Dion, Berscheid \& Walster, 1972; Ekman \& Friesen, 1971; Evans, Rutberg, Carmela \& Charli, 1991; Landis, 1924; Mills, 1984; Walther, Slovacek \& Tidwell, 2001). Além disso, ainda na função de modelo, a fotografia vem sendo empregada em diferentes métodos de pesquisa, inclusive como instrumento acessório de questionários ou entrevistas. Recentemente, isto foi observado em um estudo cujo objetivo era analisar as explicações, fornecidas por crianças em situação de rua, sobre desigualdades sociais (Maciel, Brito \& Camino, 1998). Participaram, deste trabalho, 56 crianças e adolescentes, com idades entre 12 e 17 anos. Durante a coleta de dados, utilizou-se um questionário, complementado por um conjunto de fotos sobre conjunturas sociais que fundamentam diversas questões sobre as desigualdades sociais. Ao longo da aplicação do questionário, as fotografias eram apresentadas, funcionando como modelo das situações em análise. As imagens retratavam quadros de pobreza e de riqueza, a partir das quais, os participantes expunham as explicações sobre tais fenômenos. Neste estudo, a grande vantagem encontrada no uso da fotografia foi a riqueza de informações encontradas nas próprias imagens. Partindo-se da possibilidade de que nem todos os participantes tivessem acesso à escola, o uso de sentenças descritivas pode fazer referência a situações muito abstratas. Em contrapartida, a imagem se relaciona a informações mais concretas, o que pode enriquecer a compreensão de crianças e adolescentes em situação de rua sobre o objeto estudado.

A utilização da fotografia na pesquisa se estendeu a diversas outras áreas da Psicologia, dentre elas, a clínica. O primeiro trabalho publicado ilustrando o uso da fotografia na clínica psicológica foi desenvolvido por Gosciewski (1975) e pode ser entendido como um antecessor do método autofotográfico. Segundo o autor, uma adolescente estava há várias semanas em terapia, cujas sessões se caracterizavam por uma quase total ausência de comunicação entre o terapeuta e a paciente. Observando que ocorria uma mudança no tipo de relação entre as pessoas quando elas começavam a compartilhar fotos pessoais, o pesquisador notou que surgia uma certa empatia entre aquele que mostrava e o que observava as fotografias. Decidiu então solicitar à adolescente que, a partir do conjunto de fotos pessoais disponíveis, selecionasse algumas e trouxesse para a sessão. Em pouco tempo, a relação terapeuta-paciente foi significativa- mente modificada. Segundo o autor, as fotografias oferecem uma grande riqueza de informações sobre a vida da pessoa, tanto em aspectos ambientais quanto relacionais, permitindo conhecer diferentes contextos e acontecimentos que dificilmente o terapeuta teria acesso.

O recurso fotográfico é especialmente rico com crianças e adolescentes que, de forma freqüente, têm uma certa dificuldade em expressar verbalmente seus diferentes contextos de vida e relações sociais (Gosciewski, 1975). Nestes casos, é despertada a curiosidade e as crianças começam a contar histórias sobre o que ocorreu naquela situação, cabendo ao pesquisador aprofundar as informações sobre a percepção infantil dos diferentes aspectos, presentes ou não na imagem.

Existem três principais vantagens em se utilizar a fotografia nas pesquisas em Psicologia clínica e na própria terapia (Gosciewski, 1975). Primeiro, o processo de mostrar e ver as fotos é usado no estabelecimento do rapport entre o terapeuta e o paciente. Quando o terapeuta se mostra interessado e faz perguntas que estimulam a pessoa a falar, isto faz com que o paciente se sinta à vontade e a comunicação seja espontânea, alcançando um nível mais pessoal. $\mathrm{O}$ autor afirma ainda que as pessoas tendem a desenvolver abertura à comunicação e confiança no terapeuta mais rapidamente, quando se utiliza as fotografias neste início do processo terapêutico. Quando questionados sobre os sentimentos ao manusear as fotos durante as sessões, os pacientes informaram que sentiram o terapeuta de uma forma próxima. Além disso, relataram ter a impressão de que o terapeuta os conhecia de uma forma rápida e profunda, ao fazer com que se sentissem relaxados, sendo eles mesmos.

A segunda principal vantagem de utilizar a fotografia na pesquisa em Psicologia clínica refere-se ao estabelecimento do diagnóstico, envolvendo a integração de diferentes informações sobre o paciente (Gosciewski, 1975). As fotos podem auxiliar na identificação ou verificação dos principais problemas relatados pela pessoa, inclusive trazendo à tona determinados aspectos mais difíceis de serem explicitados. Pode-se pedir que o paciente escolha as fotos que ele mais gosta e aquelas que ele não gosta, e a partir daí desenvolver uma entrevista sobre cada uma delas ou pedir para que ele escreva uma legenda sobre cada uma das fotos. A terceira vantagem diz respeito ao uso progressivo das fotos em diferentes sessões para se fazer uma avaliação dos progressos ocorridos ao longo da terapia ou do que ainda permanece como um problema. Segundo o autor, isto pode auxiliar na compreensão da natureza dos principais conflitos do paciente.

Gosciewski (1975) identificou algumas limitações no uso da fotografia ao realizar pesquisa ou intervenção na clínica psicológica. Primeiro, ao se trabalhar com populações de baixa renda, é provável que este seja um fator que interfira na quantidade de fotografias tiradas ao longo de determinado tempo, e, por conseqüência, no número de fotos disponíveis para se realizar o trabalho. Em virtude da menor disponibilidade de recursos financeiros, pressupõe-se que estas populações tirem menos fotos ao longo da vida. Segundo, como as 
fotografias são tiradas em caráter esporádico, normalmente em situações específicas, as fotos disponíveis nos álbuns de família tendem a não ser representativas do modo de vida daquela família, pois não engloba todas as condições vivenciadas por aquele conjunto de pessoas. A terceira limitação refere-se ao fato de que, apesar do terapeuta solicitar que o paciente selecione randomicamente algumas fotos, existe a tendência de que estas sejam escolhidas, priorizando aquelas que apresentem uma melhor auto-imagem da pessoa ou da família. Dificilmente alguém escolheria uma foto ruim ou aquela tirada após algum evento negativo no contexto familiar. Segundo o autor, esta característica pode até ser útil para identificar o self ideal de uma pessoa, mas não corresponderá à realidade vivida pelo paciente.

Além das limitações apontadas pelo próprio Gosciewski (1975), foram levantadas quatro críticas principais ao método utilizado por ele (Amerikaner et al., 1980). Primeiro, os dados são limitados pelas fotografias que estão disponíveis ao paciente. Seria necessária uma ampla variabilidade de fotografias com conteúdo significativo, tanto em termos quantitativos como qualitativos. Segundo, as fotografias são, na maioria dos casos, tiradas por outras pessoas, sejam elas amigos, parentes ou fotógrafos profissionais. Isto implica a impossibilidade de se ter acesso à percepção da própria pessoa, que no caso seria o foco central a ser alcançado no processo terapêutico. A terceira crítica refere-se à perspectiva de tempo. No trabalho de Gosciewski, as fotografias eram coletadas e trazidas para as sessões, sem haver uma preocupação em relação ao tempo em que elas foram tiradas. Independentemente se eram fotos da infância do paciente ou tiradas no último ano, dizem respeito ao passado. Os autores que sustentam esta crítica afirmam que este material só é válido, caso o terapeuta esteja interessado em fazer um levantamento de dados históricos ou em reconstituir o contexto social de desenvolvimento do paciente. O problema está no fato de que estas fotos do passado são limitadas no que diz respeito às informações sobre o presente, ou seja, como a pessoa percebe e funciona no momento em que ocorre a terapia. A quarta crítica baseia-se no quão difícil é para o paciente organizar os dados de uma maneira que seja significativa e relevante, uma vez que as fotos são tiradas em caráter esporádico, na maior parte das vezes por outras pessoas, em diferentes momentos, e recordadas por motivos distintos.

O trabalho de Gosciewski (1975), apesar de ter sido fortemente criticado, introduziu o uso da fotografia na prática de muitos psicólogos que trabalhavam com psicoterapia na época, e, provavelmente, influenciou a criação e o desenvolvimento do método autofotográfico. Este foi, inicialmente, descrito por Robert Ziller no final da década de 70 (Ziller \& Smith, 1977). Neste artigo, os autores apresentam três estudos nos quais o indivíduo é solicitado a apresentar uma série de fotografias tiradas por ele, descrevendo visão de um ambiente particular ou de si mesmo. É proposto que o participante, aquele que percebe o mundo de uma determinada forma, seja agora percebido através da sua fotografia. No primeiro estudo, Ziller e Smith tiveram por objetivo explorar a percepção do ambiente por pessoas que se diferenciam em termos de familiaridade com o local onde vivem ou freqüentam. Os participantes foram reunidos em dois grupos, um de pessoas novatas, que habitavam a cerca de um mês em determinado lugar e um outro grupo de pessoas que já viviam em torno de sete meses no lugar. Os autores basearam-se no pressuposto que pessoas com diferentes níveis de familiaridade com o mesmo ambiente prestam atenção a características ambientais distintas. Cada participante recebeu uma câmera automática, com um filme de 12 poses e foi pedido que descrevesse o seu ambiente como o via através das fotografias. As imagens do grupo de novatos foram comparadas com as do outro grupo e foram classificadas em três categorias: pessoas, paisagens naturais e paisagens artificiais, nas quais se incluíam edifícios e outras construções. A análise de confiabilidade entre juízes foi de $90 \%$. Os dados mostraram que os mais antigos tiraram mais fotos de pessoas do que os novatos, que se ativeram mais às paisagens. Os resultados sugerem que ocorre uma mudança na percepção do ambiente ao longo do tempo e confirmam a hipótese inicial de que há diferenças nas características observadas. As pessoas novatas tendem a se orientar mais pelos edifícios e paisagens e aquelas mais antigas tendem a prestar mais atenção a outras pessoas. Um aspecto observado foi que apenas estudantes negros tiraram fotos de pessoas negras, o que, segundo os autores, faz menção à possível discriminação racial presente. Este fato pode ter ocorrido também devido ao tipo de interações existentes entre os indivíduos naquele ambiente.

Neste primeiro estudo (Ziller \& Smith, 1977) foi explicado que a atividade faria parte de um projeto de classe da Universidade, não fazendo menção que os participantes estariam envolvidos em uma pesquisa. Apesar dos autores não justificarem esta omissão aos participantes, este procedimento é hoje bastante questionável em termos éticos. Tem-se adotado como norma, que o participante deva sempre ter conhecimento de sua participação em uma pesquisa, salvo os casos em que este fato venha a interferir de forma significativa sobre os resultados, inviabilizando o estudo (Barker, Pistrang \& Elliot, 1994; Conselho Federal de Psicologia, 2000).

No segundo estudo do artigo de Ziller e Smith (1977), foi investigada a percepção de pessoas portadoras de deficiência locomotora que utilizam cadeira-de-roda comparada com a visão de pessoas que não apresentam esta limitação. Os procedimentos foram os mesmos utilizados no primeiro estudo. Dentre os resultados, destaca-se o fato de que apenas uma única foto tirada pelos usuários de cadeira-de-rodas mostrava contato visual entre a pessoa que tirava a foto e a que era fotografada. Em todas as outras, as pessoas não olhavam para quem estava na cadeira-de-rodas. Por outro lado, quase metade dos conjuntos de fotos tiradas pelas pessoas não-portadoras de deficiência apresentava contato visual. Esta tendência é especialmente exemplificada por duas fotos. Na primeira, existe uma aglomeração de pessoas a poucos metros de distância e nenhuma delas estabelece contato visual. Na segunda, o portador de deficiência registra o fato de que, em meio a uma multidão na qual nenhuma pessoa esta- 
belece contato direto com os olhos do participante, apenas um cachorro está parado e olha para os seus olhos. Segundo os autores, existe uma certa evitação por parte das pessoas que não possuem problemas locomotores em relação aos portadores de deficiência. As pessoas em cadeira-de-rodas "vêem corpos sem olhos. O resultado não é uma coletânea de pessoas em uma multidão, mas uma parede de pessoas" (Ziller \& Smith, p.178). Os pesquisadores sugerem a extensão deste método para melhor compreender pessoas que apresentam dificuldade na comunicação de suas percepções do mundo, assim como crianças, idosos ou pessoas com depressão.

No terceiro estudo (em Ziller \& Smith, 1977), diferenças de gênero na auto-representação de estudantes universitários são analisadas. Homens e mulheres, com idades variando entre 19 e 21 anos, foram solicitados a tirar 12 fotos em resposta à pergunta “Quem é você?”. Após ser realizada a análise de conteúdo das imagens, foram criadas categorias como estudo, plantas, animais, pessoas do sexo oposto e fotos de si mesmo. As fotografias foram classificadas segundo estas categorias. Os dados mostraram que as fotos femininas estavam mais associadas a plantas, animais, fotos de si mesmas e atividades como cozinhar. As fotos masculinas estavam mais associadas a imagens de esporte, como por exemplo, motocicletas.

O primeiro trabalho que usou a questão "Quem é você?" (Kuhn \& McPartland, 1954, citado em Ziller \& Smith, 1977) não fazia referência ao uso da fotografia. Neste estudo, era solicitado que os participantes escrevessem 20 diferentes respostas para a pergunta citada. Ziller e Smith afirmam que o método autofotográfico apresenta a característica de não depender da habilidade verbal ou escrita, o que implica uma maior possibilidade da expressão do self sem as usuais limitações impostas pela linguagem verbal. Os autores apontam a vantagem da fotografia documentar a percepção do participante, com um mínimo de treino, evitando as desvantagens usuais das técnicas de relato verbal. É ressaltada, ainda, a vantagem de não ser o pesquisador quem direciona ou induz o olhar do participante para determinada categoria de resposta. É o próprio participante quem seleciona os estímulos. Existe uma mínima interferência do pesquisador na forma do participante perceber o mundo, evitando assim o viés das expectativas sociais, bastante comuns em entrevistas. Este trabalho de Ziller e Smith (1977) é de grande importância, pois se torna referência para trabalhos subseqüentes que vêm, tanto usar o método autofotográfico, como também trabalhar com a questão de identidade através da pergunta "Quem é você?".

Uma outra primeira pesquisa que utiliza o método autofotográfico na área clínica aborda o autoconceito de pessoas que faziam terapia (Combs \& Ziller, 1977). Os pacientes eram solicitados a tirar 12 fotos em resposta à questão "Quem é você?". Cada participante recebia uma câmera e era orientado para que não se preocupasse com as suas habilidades fotográficas, mas que centralizasse a sua atenção em representar, da melhor forma possível, as respostas para a questão colocada. Uma vez revelado o filme, era solicitado às pessoas que numerassem as fotos em ordem crescente de importân- cia, começando por aquela que fosse mais representativa e que melhor ilustrasse a resposta à questão colocada. As fotos eram, então, categorizadas através de análise de conteúdo, tomando por base o tema central de cada uma delas. Os dados foram comparados com as fotos de um grupo que não estava em terapia. Os resultados mostraram que as pessoas em terapia tiraram um número de fotos significativamente maior sobre o passado e sobre suas famílias. Por outro lado, foi significativamente menor o número de fotos sobre si mesmos. Estes dados foram usados no próprio processo terapêutico, pelo qual foram identificados, através de entrevista, alguns pacientes com baixo índice de auto-estima e ampla não-aceitação da aparência física.

Segundo Combs e Ziller (1977), as diferenças entre o grupo de pacientes e o grupo controle foram de tal modo significativas que atestaram a validade do método e a sua ampla utilização como uma técnica de pesquisa. Foi apontada como vantagem da utilização do método autofotográfico o fato deste ter facilitado a comunicação entre os pacientes e o terapeuta na expressão de conteúdos difíceis de serem verbalizados, como por exemplo, a não-aceitação da auto-imagem. Considerou-se também positivo o fato da técnica ser simples e facilmente aceita pelos pacientes, pela qual é possível a representação de si mesmos de uma maneira gratificante e prazerosa. Foi ressaltada a qualidade de superar as barreiras e limitações usuais encontradas na linguagem verbal. Utilizando o método autofotográfico, Amerikaner et al. (1980) desenvolveram uma pesquisa também com pessoas submetidas a psicoterapia. Foram adotados os mesmos procedimentos no processo de manipulação das fotos durante as sessões terapêuticas e as mesmas instruções dadas aos participantes por Combs e Ziller (1977). Contudo, após as fotos serem reveladas e enumeradas segundo o critério de representatividade, os participantes foram solicitados a montar um pôster. Esta montagem deveria seguir a sequiência de numeração das fotos e cada pessoa deveria escrever um breve comentário abaixo de cada foto, como uma legenda. De acordo com Amerikaner et al. (1980), a vantagem de se montar o pôster é permitir a visualização de todo o conjunto de fotos de uma única vez, o que é vantajoso tanto para o paciente quanto para o terapeuta, além de facilitar o armazenamento das fotos de todos os participantes sem que corra o risco destas se misturarem. A legenda, assim como a subseqüente entrevista sobre o seu conteúdo e o da foto, permite tornar claras a extensão e a natureza das inter-relações das categorias, assim como suas características periféricas ou centrais.

Com freqüência, os participantes da pesquisa buscarão maiores informações sobre as instruções fornecidas, principalmente no que diz respeito a quem deve tirar as fotos, se ele próprio ou outra pessoa (Amerikaner et al., 1980). Os autores afirmam que as instruções são dadas de uma forma intencionalmente vaga, justamente permitindo à pessoa a decisão de quem será o autor da fotografia. Cabe ao participante decidir se ele próprio irá tirar a foto ou se ele fará parte da foto. Neste último caso, estando presente na imagem a ser captada, é necessário que o participante peça a alguém para tirar a foto. 
Faz-se necessário enfatizar que a fotografia deve ser sobre qualquer coisa que ajude a descrever como a pessoa vê a si mesma e que os conhecimentos, habilidades e experiência em fotografia não são importantes para o resultado do estudo. Com base nestas informações, é possível que seja registrada uma imagem na qual o próprio participante esteja presente.

A partir do desenvolvimento destes estudos, Amerikaner et al. (1980) sugerem a existência de dois grandes fatores que devem ser considerados, prioritariamente, no uso da fotografia na pesquisa psicológica: o conteúdo e o processo. $\mathrm{O}$ conteúdo refere-se às fotografias em si, às imagens tomadas individualmente, sejam de pessoas, lugares, atividades ou qualquer objeto ou evento que a pessoa julgar importante na percepção de si mesmo. Este conteúdo pode se referir, por exemplo, a um aspecto afetivo que vai além da cena concreta que está sendo visualizada. Isto se torna mais nítido quando as fotografias são vistas como um conjunto. Este aspecto auxilia o terapeuta a ter acesso aos sentimentos do paciente, como também estimula a própria pessoa que está em terapia a falar sobre seus sentimentos e emoções.

Conteúdos extremamente significativos para a pesquisa podem surgir exatamente do que foi omitido nas fotografias (Amerikaner et al., 1980). Isto ocorre quando categorias inteiras são omitidas em todas as fotos. Determinadas categorias, freqüentemente, estão presentes em grande parte dos integrantes de um mesmo grupo de uma pesquisa, como por exemplo, fotos de si mesmo, ou de familiares. $\mathrm{O}$ fato de nenhum destes conteúdos surgir, em determinado conjunto de fotos, pode indicar, principalmente em um contexto clínico, que estes temas podem ser significativos para aquela pessoa, mas que são difíceis de serem verbalizados. Outro exemplo é visto quando o paciente ou o participante da pesquisa relata determinado aspecto como sendo central em sua vida, mas este é omitido do conjunto de fotografias. Esta aparente contradição pode ser explorada na entrevista, auxiliando a pessoa a lidar com estas questões, tornando-as explícitas.

O segundo fator considerado prioritário no uso da fotografia na pesquisa psicológica é o processo (Amerikaner et al., 1980). Os autores afirmam ser esta a dimensão que caracteriza a forma como a pessoa interage, responde e compreende o mundo ao seu redor. É necessário que o pesquisador modifique a maneira de analisar as fotografias, variando o foco de atenção entre o significado concreto e o abstrato, entre uma única fotografia e o conjunto delas.

Determinadas pessoas podem, por exemplo, falar sobre cada foto individualmente, esquecendo-se de analisar o que representa o todo, ou seja, o conjunto formado pelo agrupamento das fotos, sendo que o contrário também pode ocorrer. De forma semelhante, haverá pessoas que, tanto no momento de escrever a legenda, como no ato de falar sobre as imagens, ater-se-ão apenas ao aspecto concreto, literal das fotos, como por exemplo, uma casa, um carro, os amigos ou o local de trabalho, em detrimento da compreensão do significado destas imagens. O oposto ocorre com pessoas que, hipoteticamente, fotografam nuvens, obras de arte, pássaros voando. Elas enfocam apenas o lado abstrato das imagens ao invés de enfocar também o aspecto concreto de suas vidas. É necessário, nestes casos, que as pessoas pensem sobre como as imagens podem se vincular ao lado real, tangível de suas vidas. Em suma, de acordo com Amerikaner et al. (1980), durante a análise das fotos é importante que o pesquisador, junto com o participante, perpasse diferentes aspectos, desde o abstrato até o concreto, partindo da análise individual de cada foto e chegando à compreensão do conjunto delas.

O método autofotográfico permite que outras dimensões da fotografia sejam também exploradas (Amerikaner et al., 1980), como por exemplo, o aspecto temporal, ou seja, o nível em que as imagens se relacionam com o passado, presente ou futuro da vida da pessoa. Esta perspectiva de tempo pode fornecer importantes subsídios para a psicoterapia, tornando claro como esta dimensão pode estar relacionada a problemas vivenciados pelo paciente. Um exemplo concreto é encontrado nas fotografias de uma das participantes da pesquisa de Amerikaner et al. (1980), recém-divorciada, após 10 anos de casamento. Em relação ao tempo presente, as fotos indicavam um mundo frio, isolado, doloroso e confuso. Os únicos pontos de referência remetiam ao passado. $\mathrm{O}$ futuro mostrava-se obscuro e cheio de contradições. Uma das fotos indicava uma placa com os nomes de diversas cidades apontando para diferentes direções. Não havia uma única foto de si mesma. As únicas pessoas presentes nas imagens eram desconhecidas e estavam distantes e sozinhas. Em contrapartida, as fotos de uma outra participante recém-formada e esperando seu primeiro filho apresentaram um conteúdo significativamente diferente, enfocando pessoas, grupo de amigos e atividades. Quase metade das fotos incluía imagens de si mesma, em diferentes papéis. Esta descrição das diferentes características das fotografias de duas participantes mostra apenas algumas das possibilidades de uma entrevista que toma por base o conjunto das fotografias obtidas pelo método autofotográfico.

Amerikaner et al. (1980) concluem o seu trabalho afirmando que o método autofotográfico provê uma rica fonte de dados a serem utilizados nas diferentes fases do processo terapêutico. Os autores levantam um questionamento sobre a adequação do método a todos os tipos de pessoas. Uma vez que cada pessoa processa e comunica as informações de modo diferenciado, seja priorizando o sistema visual, auditivo, cinestésico, gustativo ou olfativo, espera-se que a abordagem autofotográfica seja mais indicada àquelas pessoas orientadas predominantemente pela visão. Desta forma, o método pode ser especialmente útil para aqueles que possuem um processamento visual subdesenvolvido, uma vez que este poderia estimulá-lo.

Além da clínica psicológica, o método autofotográfico foi também utilizado no estudo da delinquiência juvenil (Ziller \& Lewis, 1981). A idéia de "delinqüência" foi relacionada a adolescentes que apresentavam comportamento anti-social ou que estavam envolvidos com a justiça criminal. Os autores utilizaram o construto "orientação", se referindo a "comportamentos envolvidos em processos de autodefinição, no qual o ambiente é examinado em busca de pontos de referên- 
cia pessoais e fontes disponíveis de auto-reforçamento" (Ziller \& Lewis, p. 338). Estes pontos de referência pessoais incluem pessoas, objetos e símbolos ligados aos valores da própria pessoa. Um grupo de 35 garotos "delinqüentes", que viviam em liberdade, moravam com a família e estavam matriculados em uma escola especial, foi comparado a um grupo de 44 estudantes de uma escola pública regular, com o objetivo de analisar suas diferentes "orientações". Todos eram do sexo masculino e tinham idades entre 11 e 17 anos. Foram utilizados os procedimentos básicos do método autofotográfico (Combs \& Ziller, 1977; Ziller \& Smith, 1977). Os resultados mostraram que o grupo de "delinqüentes", ao contrário do grupo controle, apresentou um número bem menor de fotografias ligadas à escola ou aos livros, mostrando haver uma redução dos recursos de aceitação social e de auto-reforçamento, normalmente ligados à valorização da educação. O grupo de "delinqüentes" apresentou também um número significativamente maior de fotos que mencionavam pessoas, especificamente aquelas integrantes do seu grupo. Isto indica uma grande valorização do significado de pertencimento ao grupo e reconhecimento advindo de seus pares, que tende a suprir a ausência do prestígio normalmente oriundo da inserção na escola. Ziller e Lewis afirmam que os comportamentos delinqüentes aparecem menos influenciados pelos controles institucionais, como o lar e a escola, e mais influenciados pelos controles sociais, como por exemplo, o de seus pares.

Outras pesquisas também foram desenvolvidas com o uso da fotografia enfocando a delinqüência entre adolescentes (Fryrear, Nuell \& Ridley, 1974; Fryrear, Nuel \& White, 1977). Contudo, observam-se significativas diferenças com relação ao método. Nestes trabalhos, a fotografia teve uma função diferenciada, sendo utilizada como instrumento de feedback. Um dos estudos teve como objetivo avaliar a melhoria do auto-conceito de adolescentes delinqüentes através da fotografia (Fryrear, Nuell \& Ridley). Partiu-se do pressuposto de que se estes jovens, possuidores de autoconceito negativo, são auxiliados a se verem de uma forma diferenciada, seus autoconceitos seriam melhorados e, conseqüentemente, seus comportamentos se tornariam socialmente mais aceitos. Selecionou-se 30 participantes do sexo masculino, com idades entre 13 e 16 anos, que estavam cumprindo medida restritiva de liberdade em uma instituição norte-americana. Estes foram divididos em dois grupos, e todos foram submetidos a uma avaliação de auto-conceito através do Tennesse Self-Concept Scale - TSCS (citado em Fryrear, Nuell \& Ridley). Foram feitas fotografias individuais de cada um dos participantes de apenas um dos grupos, em cinco sessões diferentes. Após cada sessão, as fotografias eram entregues aos participantes que eram solicitados a montar um álbum. Paralelamente, foi entregue ao grupo-controle um conjunto de revistas de automóveis e motocicletas, e solicitado para que estes montassem um álbum com figuras recortadas. Depois da montagem de todos os álbuns, os grupos foram submetidos novamente ao TSCS. Os dados mostraram que, em comparação com o grupo controle, o que recebeu feedback atra- vés das fotografias aumentou significativamente o autoconceito, a autosatisfação e o uso de defesas psicológicas necessárias à manutenção da auto-estima. Segundo os autores, a fotografia tem a vantagem de ser um registro visual permanente que permite ao indivíduo ver a si mesmo de uma forma objetiva, algo importante para o desenvolvimento do autoconceito. Através deste estudo (Fryrear, Nuell \& Ridley), verificam-se diferenças importantes entre o método autofotográfico e o uso da fotografia como instrumento de feedback. Neste, não era o adolescente quem tirava a sua própria foto, mas outras pessoas o faziam. Observa-se que não há uma preocupação com o autor da foto, mas apenas com o resultado que esta gera sobre o participante da pesquisa. Já na função autofotográfica, importa tanto o autor da foto quanto a sua percepção a respeito das imagens registradas pela própria pessoa. Nestes casos, o conteúdo das fotografias pode incluir qualquer ação, pessoa, objeto, símbolo ou lugar escolhidos pelo participante para representar uma idéia ou conceito.

Trabalhando também com adolescentes, Ziller, Vern e de Santoya (1988) desenvolveram uma pesquisa com o objetivo de analisar a diferença entre níveis sócio-econômicos através do método autofotográfico. A amostra foi composta por 29 estudantes de ambos os sexos, com idades variando entre 12 e 13 anos, e que moravam com suas famílias. O primeiro grupo, denominado "pobre", era formado de 14 participantes, moradores de regiões de nível sócio-econômico baixo, em que a grande maioria das residências não possuía água encanada. O segundo grupo, denominado "abastado", era formado de 15 adolescentes oriundos de regiões habitacionais de nível médio-alto. Foram utilizados os procedimentos básicos do método autofotográfico (Combs \& Ziller, 1977; Ziller \& Smith, 1977), enfatizando que o principal objetivo era que as fotografias descrevessem como os adolescentes viam a si mesmos. Foi realizada análise de conteúdo quantitativa das fotos, e estas, classificadas em 18 categorias.

Os resultados de Ziller et al. (1988) mostraram diferenças significativas entre o grupo "pobre" e o "abastado". As diferenças mais extremas se deram entre o sexo masculino do grupo "abastado" e o sexo feminino do grupo "pobre". A percepção das meninas "pobres", como observado pela análise das fotografias, mostra um mundo estreito, limitado e não envolvendo o self. Estas meninas não apresentaram nenhuma foto que mostrava a si mesmas, tampouco de atividades cotidianas, jogos ou brinquedos. Apesar de apresentarem o mínimo de bens materiais, elas mostraram o maior número de fotos fazendo referência a outras pessoas, grupos e multidões.

Segundo Combs e Ziller (1977), a inclusão de si mesmo na fotografia é um sinal de auto-estima. Por outro lado, a ausência total de imagens de si mesmo, como observado no conjunto de fotos apresentadas pelas meninas "pobres", tende a ser compreendida como um sinal de baixa auto-estima. Este dado faz sentido quando inserido no contexto da sociedade contemporânea, no qual a beleza estética é estereotipada e, principalmente no período da adolescência, supervalorizada. 
Como os recursos financeiros destas garotas não lhes dão condições de manter a aparência de acordo com o desejado, é compreensível que as mesmas não queiram ver ou mostrar suas próprias imagens através das fotografias.

Outro dado passível de ser compreendido, quando considerado o contexto onde vivem as garotas "pobres", diz respeito à quantidade de fotografias destas meninas envolvendo grupos de pessoas. De acordo com Ziller et al. (1988), elas vivem em uma conjuntura na qual é necessária a valorização de um sistema de apoio social. $\mathrm{O}$ isolamento confere maior vulnerabilidade ao indivíduo que vive em condição de pobreza. As chances de que estas adolescentes tenham êxito em seu ambiente de origem dependem do quanto elas podem contar com a ajuda daqueles que as cercam.

Através das imagens apresentadas pelos adolescentes, compreende-se o mundo dos garotos "abastados" como sendo sem limitações e com uma certa auto-exaltação (Ziller et al., 1988). Todos os garotos "abastados" apresentaram fotos deles próprios, assim como a maioria de suas fotografias indicava músicas, atividades artísticas, aulas na escola, bens materiais, jogos e brinquedos. Contudo pouquíssimas fotos faziam referência a outras pessoas e a grupos. Esta percepção de mundo dos garotos "abastados" é compreendida pelos autores como sendo funcional, uma vez que eles estão inseridos em uma sociedade competitiva, que valoriza o status e a afirmação de si mesmo. A ausência da menção a outras pessoas ou grupos, juntamente com a excessiva referência a bens pessoais, reflete o contexto onde são criadas estas crianças. Isto pode ser observado através da fala de uma delas: "Eu não sou como muitas outras crianças. Eu sei disso. Nós vivemos distantes de outras pessoas e nós não vemos muitas pessoas. Meus pais gostam de sua privacidade" (Coles, 1964, p. 527, citado em Ziller et al., p. 38). Estas crianças são educadas a brincar dentro de suas residências com seus brinquedos, mas relativamente distantes dos grupos de seus pares. Como indicado pelas fotografias, a única menção a outras crianças ocorre em relação à escola, local destinado de forma propícia para o contato seguro com seus amigos. Segundo Ziller et al., a lacuna deixada pela falta de contato com os pares acaba sendo preenchida pela disponibilidade de atividades e bens pessoais como livros e brinquedos.

Ao considerar a utilização do método autofotográfico nesta pesquisa, algumas limitações foram encontradas (Ziller et al., 1988). Foram utilizadas câmeras fotográficas sem o dispositivo de iluminação do flash. Isto fez com que algumas fotografias tiradas em ambientes interiores, com pouca luz, fossem perdidas. Outro problema refere-se ao número reduzido de participantes, assim como o pequeno número de fotografias tiradas por cada um deles, que acabou gerando uma certa dificuldade na análise estatística dos dados. De acordo com os autores, os maiores problemas estão vinculados ao processo de paráfrase, a partir das categorias das fotos para a interpretação das mesmas. Compreende-se que o principal motivo desta limitação é a não realização de entrevistas com os participantes, nas quais cada um deles poderia falar sobre o significado de suas próprias fotos. Ao realizar este procedi- mento, seria minimizado o problema de uma interpretação das imagens apenas com bases inferenciais.

O método autofotográfico é comparado a outros métodos de pesquisa que buscam a compreensão da linguagem não verbal, como por exemplo, o desenho (Ziller et al., 1988). Este último, bastante usado com crianças, tem a grande vantagem de ser algo divertido e prazeroso para ser realizado com os participantes. Contudo, o desenho exige um nível de habilidade motora e gráfica significativamente grande. Já a comunicação através da fotografia ocorre de uma forma extremamente simples, sem a exigência de grandes habilidades, e mantém a vantagem do grande interesse das crianças pelo fruto do seu próprio trabalho, as fotos.

A pesquisa de Ziller et al. (1988) é de grande importância, não só pelo conteúdo de seus resultados, mas principalmente pela contribuição metodológica na pesquisa psicológica com crianças. Uma das maiores dificuldades encontradas em pesquisas com esta população é a limitação da linguagem verbal. Dependendo da idade da criança com a qual se trabalha e do tema a ser investigado, se torna bastante complexo, às vezes impossível, entrevistar uma criança para verificar a sua compreensão acerca de determinado tema. A criança, muitas vezes, necessita do ambiente ao seu redor para se expressar, se não pelas palavras, através das imagens. "Somente pessoas, objetos, cenas e símbolos podem ser fotografados, e estes são encontrados no ambiente das pessoas" (Ziller et al., p. 39). Neste sentido, o método autofotográfico se mostra bastante adequado tanto pela simplicidade de seu processo, pela riqueza de conteúdo trazida pelas fotografias, como pela superação de barreiras sociais e culturais normalmente trazidas pela linguagem verbal.

A superação de barreiras sociais também ocorreu ao pesquisar, através da fotografia, a percepção de adolescentes que viviam em uma favela na cidade de Fortaleza, Brasil, sobre a realidade da vida de rua (Monteiro \& Dollinger, 1996, 1998). Os participantes deste estudo, dez meninos e dez meninas com idades variando entre dez e 15 anos, foram entrevistados e posteriormente solicitados a tirar dez fotos em resposta à pergunta "Quem é você?". Análise de conteúdo classificou as fotos em 49 categorias, cujo índice de fidedignidade entre juízes foi de 0,90 . Os resultados foram reunidos em três temas centrais. O primeiro, descrito como ambiente físico, envolve a percepção do que vem a ser a pobreza, a vida na rua e a noção de limites. Encontraram-se registros de crianças usando drogas, assim como as condições precárias das habitações de origem. $\mathrm{O}$ segundo tema central refere-se às relações sociais, principalmente entre amigos e parentes. Assim como Ziller et al. (1988), Monteiro e Dollinger (1996) encontraram alta frequiência de imagens fazendo referência a grupos de pessoas, principalmente a outras crianças em situação de pobreza. De acordo com a fala de um dos garotos, "o grupo é muito importante para mim" (Monteiro \& Dollinger, p. 54). O terceiro tema central aborda a noção de identidade e identificações, referindo-se a projetos futuros, identificações sexuais e valores filosóficos. Fotos de adolescentes masculinos e femininos faziam forte referência à sexualidade, assun- 
to bastante presente em virtude da fase de desenvolvimento em que os participantes se encontravam e dos seus contextos de vida.

Segundo Monteiro e Dollinger (1996), os participantes mostraram grande entusiasmo e interesse em relação ao uso da fotografia, dificilmente encontrados na utilização de instrumentos como questionários e entrevistas. O método autofotográfico mostrou-se fortemente recomendável às pesquisas cuja população alvo são crianças em situação de risco. O trabalho de Monteiro e Dollinger é destacado pelo fato de ser um dos poucos trabalhos publicados que faz referência ao uso da fotografia na pesquisa psicológica desenvolvida no Brasil.

Barreiras culturais foram encontradas ao se investigar a compreensão de crianças alemãs e norte-americanas sobre o significado de guerra e paz (Dinklage \& Ziller, 1989). Nesta pesquisa, observou-se que Estados Unidos e Alemanha estão distantes tanto geográfica como culturalmente, pois se encontraram diferenças significativas na forma de compreender os referidos significados. De acordo com os autores, "o significado do conceito pode ser comunicado através de imagens fotográficas, que localizam os conceitos no contexto" (p. 309). Participaram do estudo 40 estudantes do sexo feminino e 40 do sexo masculino, com idades entre oito e dez anos. Metade do grupo era da cidade de Orlando, na Florida e a outra parte, de Bremerhaven, antiga Alemanha Ocidental. Foi entregue a cada criança uma câmera com flash, e solicitado que cada uma delas tirasse uma foto representando o conceito "paz" e uma foto representando "guerra". Posteriormente, foi conduzida uma entrevista estruturada onde se perguntava qual das fotos se relacionava ao conceito de "paz" e qual estava ligada ao conceito de "guerra". Perguntou-se, também, o que a foto indicada como "paz" representava para a criança. $\mathrm{O}$ mesmo procedimento foi repetido para a foto indicada como "guerra". Os resultados entre os grupos foram significativamente diferentes. Para as crianças alemãs, o significado de guerra é mais freqüentemente associado a imagens de destruição de propriedades, danos, prejuízos e morte. Já o conceito de paz é mais freqüentemente associado a imagens de pessoas. Para as crianças norte-americanas, guerra foi associada a outros aspectos, não explicitados pelos autores, enquanto que paz foi mais freqüentemente relacionada com natureza. Os dados levam à compreensão de que para as crianças alemãs, a guerra é muito mais ameaçadora, pois além de toda a destruição de suas próprias cidades, existe a possibilidade de morte tanto para elas quanto para seus familiares. Já para as crianças norte-americanas, pelo menos na época em que foi realizada a pesquisa, a guerra não era vista como tão ameaçadora, pois pelo fato de estar sempre distante, parecia irreal e não afetaria diretamente as suas vidas e nem a de seus familiares.

Hoje, depois dos atentados ocorridos nos Estados Unidos, talvez fosse elucidativa a replicação deste estudo, para verificar o quanto a ocorrência de tais eventos interferem na percepção das crianças sobre seu mundo. As diferenças no significado do conceito "guerra" podem trazer implicações para diferentes abordagens dos conflitos internacionais (Dinklage \& Ziller, 1989). Segundo os autores, a compreensão das diferenças de significado dos conceitos de guerra e paz pode, inclusive, influenciar o processo de entendimento entre os países envolvidos.

O método autofotográfico apresenta algumas limitações, como por exemplo, a disponibilidade de pessoas, cenas ou objetos apropriados para representar os diferentes conceitos e o número reduzido de participantes (Dinklage \& Ziller, 1989). Contudo, de acordo com os autores, a grande contribuição deste método para as pesquisas trans-culturais é a universalidade da linguagem fotográfica, que supera os problemas de comunicação da linguagem verbal existentes, principalmente entre culturas com idiomas diferentes.

A fotografia foi também usada em outro estudo transcultural (Okura et al., 1985-86). Tal pesquisa investigou o processo de envelhecimento nas culturas japonesa e norteamericana. A amostra foi composta de 30 japoneses e 30 norte-americanos de ambos os sexos, com idade média de 73 anos. Foi utilizado o método autofotográfico (Combs \& Ziller, 1977; Ziller \& Smith, 1977), e solicitado aos participantes a responderem à questão "Quem é você?". Foi realizada análise de conteúdo das fotografias e estas foram classificadas em 24 categorias. Em 75\% destas, o índice de fidedignidade de juízes variou entre 0,72 e 0,98 . Os resultados mostraram que os idosos japoneses, em contraste com o outro grupo, mostraram-se mais internamente orientados, fazendo referência ao self e a seus próprios lares e jardins. Por outro lado, os idosos norte-americanos apresentaram-se mais externamente orientados, valorizando sempre outras pessoas, tanto do sexo masculino quanto feminino, assim como outros idosos.

Após uma longa discussão sobre diferentes concepções de pessoas, lugares e objetos nas culturas japonesa e norteamericana, Okura et al. (1985-86) concluem que a diferença encontrada nos resultados se refere à divergência de significados em relação ao conceito de "paz". Segundo os autores, o conceito de paz é visto na cultura japonesa como sendo fruto de uma busca interior, da sabedoria adquirida com o tempo e conquistada pelo envelhecimento da pessoa. Em contraste com a concepção oriental, o conceito de paz no ocidente, como observado através das fotos, tende a ser interpretado como sendo externo ao sujeito, resultado da interação de forças sociais em oposição.

Novamente destaca-se a flexibilidade do método autofotográfico, na medida em que permite a comunicação de duas culturas tão diferentes como a japonesa e a norte-americana. Ressalta-se ainda a amplitude de idades dos participantes abarcada pelo método citado. Indivíduos com idades variando de seis a 104 anos seguiram os procedimentos e completaram as tarefas solicitadas com êxito (Okura et al., 1985-86; Ziller \& Rorer, 1985).

Diferenças culturais também foram encontradas ao se investigar os valores individuais de 36 estudantes poloneses e 40 estudantes norte-americanos através da fotografia (Rorer \& Ziller, 1982). Para se analisar esta possível diferença de valores culturais, os participantes, todos com 18 anos de ida- 
de, foram solicitados a tirar três fotos que melhor representassem a noção de uma "vida boa". Segundo os autores, foram escolhidas a cultura polonesa e a norte-americana em virtude das diferenças existentes entre elas, em termos de ideologias políticas, condições econômicas e história de ambos os países. Foi feita análise de conteúdo quantitativa das fotos, e estas foram classificadas em 15 categorias. Os dados mostraram que os norte-americanos incluíram um número significativamente maior de fotografias ligadas a recreação, música, pessoas do sexo oposto, casais e nus. Os poloneses apresentaram mais imagens ligadas a crianças, escolas, lares e religião. Como se observa, a adolescência norte-americana, naquela época, era nitidamente marcada por uma reação aos padrões normativos tradicionais, enquanto que a adolescência polonesa tende a seguir os valores das instituições sociais, como família, igreja e educação.

O método autofotográfico coloca o respondente em um contexto não-familiar de comunicação, nos quais os valores de cada pessoa emergem identificados com as pessoas, objetos e símbolos presentes no ambiente (Rorer \& Ziller, 1982). Os pesquisadores afirmam que o método gera um grande enriquecimento do estudo, em virtude do grande interesse e nível de envolvimento despertados nos participantes. Isto é observado, por exemplo, no alto índice de retorno dos respondentes ao local da pesquisa para ver as suas fotografias.

Em virtude do número cada vez maior de estudos envolvendo o método autofotográfico, Henry e Solano (1983) realizaram uma pesquisa com o objetivo de desenvolver um sistema de codificação para as variáveis fotográficas e de analisar as relações entre estas variáveis e características de personalidade. 23 estudantes de ambos os sexos foram instruídos a tirar quantas fotos quisessem em qualquer lugar escolhido por eles. Foram ainda submetidos a uma bateria de testes de personalidade. As fotos foram classificadas, e a análise de confiabilidade entre juízes variou entre $60 \%$ e $95 \%$, em relação às diferentes categorias. Segundo os autores, "o sistema de codificação pode ser usado com grande sucesso pelos juízes, com um mínimo de treinamento, para extrair uma série de informações úteis a partir do conjunto das fotografias" (p. 85). Além disso, os resultados indicaram que os escores destas variáveis fotográficas estão relacionados com escores em uma variedade de medidas de personalidade. Os pesquisadores concluem que, apesar do limitado número de participantes e do contexto específico para se registrar as imagens, a fotografia é um método potencialmente útil para a pesquisa em Psicologia.

O método autofotográfico foi também utilizado em uma pesquisa sobre timidez (Ziller \& Rorer, 1985). Foi proposto que a timidez induz, e ao mesmo tempo, é induzida pela percepção que a pessoa tem do seu meio-ambiente. Em um dos estudos descritos, 29 estudantes de ambos os sexos foram submetidos a dois instrumentos de avaliação da timidez, Eysenck Introversion-Extroversion Scale - IE e Stanford Shyness Survey (Zimbardo, 1977, citado em Ziller \& Rorer), e posteriormente, solicitados a tirar 12 fotos em resposta à questão "Quem é você?". Os dados mostraram que as pessoas avali- adas como tímidas mostravam um número significativamente menor de fotos contendo outras pessoas. De acordo com os autores, o método é bastante aconselhável, na medida em que amplia a compreensão sobre a pessoa, ao considerá-la inserida no contexto específico do seu meio-ambiente.

Em uma pesquisa sobre timidez, dificilmente se conseguiria o amplo desenvolvimento de uma entrevista com pessoas com altos níveis de introspecção e/ou timidez sobre o assunto investigado. Na pesquisa de Ziller e Rorer (1985), alcançou-se informações bastante significativas através da comunicação não-verbal. A fotografia, neste caso, exerce o papel de uma metáfora. Ortony e Reynolds (1978) afirmam que a metáfora descreve uma coisa fazendo referência a outra. Segundo eles, esta figura de linguagem é bastante útil, principalmente na comunicação de coisas que não podem ser expressas literalmente ou cujo significado precisa ser construído. A fotografia transforma-se, então, em um outro canal cujos códigos passam a ser as imagens; uma forma de comunicar o que, em princípio, seria dificilmente comunicável.

A literatura aponta que o desenvolvimento do método autofotográfico na pesquisa psicológica se deu principalmente pelos trabalhos de dois pesquisadores. $\mathrm{O}$ primeiro deles, Robert C. Ziller, criou o método e, a partir dele, inúmeras pesquisas foram realizadas (Amerikaner et al., 1980; Combs \& Ziller, 1977; Dinklage \& Ziller, 1989; Okura et al., 1985-86; Rorer \& Ziller, 1982; Ziller \& Lewis, 1981; Ziller \& Rorer, 1985; Ziller \& Smith, 1977; Ziller, Vern \& de Santoya, 1988). Em 1990, publicou um livro intitulado Photographing the self, que passa a ser referência em praticamente todos os trabalhos nos quais a fotografia ocupa a função autofotográfica. Em seu trabalho mais recente, (Ziller, 2001), o autor usou a fotografia na função de modelo, e, utilizando recursos computacionais, elaborou um inventário para investigar a percepção das pessoas sobre o significado da vida.

O segundo autor que mais contribuiu para o desenvolvimento do método autofotográfico foi Stephen J. Dollinger. Dentre outros temas, este pesquisador investigou, a formação e as relações entre self, identidade e personalidade (Dollinger \& Clancy, 1993; Dollinger, Preston, O'Brien \& DiLalla, 1996), a identidade de pessoas usuárias do álcool (Dollinger, Rhodes \& Corcoran, 1993), as diferenças nas relações sociais em relação a gênero e idade (Clancy \& Dollinger, 1993), a identidade de jovens em referência ao álcool, realizações, religião e trabalho (Dollinger, 1996), as relações entre individualidade e estilos de identidade (Dollinger \& Dollinger, 1997), a criatividade e as perspectivas de vida (Dollinger, Robinson \& Ross, 1999), a experiência terapêutica e a solidão (Dollinger, Cook \& Robinson, 1999), a identidade religiosa (Dollinger, 2001), o intelecto e a individualidade (Dollinger, Ross \& Preston, no prelo) e a atratividade física, as relações sociais e a individualidade (Dollinger, no prelo).

A fotografia, utilizada na função autofotográfica, permite, ao pesquisador, o acesso a um rico conteúdo. Estas informações são obtidas basicamente de duas maneiras, a partir da análise dos dados (Dollinger \& Clancy, 1993). A primeira refere-se a uma análise mais qualitativa, na qual se considera 
um conjunto de informações presentes, não só nas imagens, como também na fala dos participantes ao expressarem suas idéias sobre as fotografias. A segunda forma remete-se a uma análise estatística, puramente quantitativa, das categorias extraídas a partir dos diferentes temas surgidos nas fotos. Segundo os autores, caso o método autofotográfico, constituído na grande maioria dos estudos por 12 fotos, fosse um teste com apenas 12 itens, haveria uma grande desvantagem psicométrica. Levando-se em consideração o reduzido número de participantes, assim como a diminuta quantidade de itens, em muitos casos pode-se não encontrar resultados estatisticamente significativos. Neste sentido, com o objetivo de aumentar o nível de confiabilidade e a validade estatística do método, Dollinger e Clancy sugerem que sejam tiradas de 20 a 24 fotos. Este objetivo pode ser também alcançado com a ampliação do número de participantes.

Quando uma pessoa direciona a câmera fotográfica para determinado objeto, símbolo, evento, pessoa ou lugar, em resposta a uma pergunta, e capta esta imagem através da fotografia, naquele instante ela passa a mostrar algo de si. $\mathrm{O}$ ato de fotografar constitui-se um importante evento social que pode afetar, inclusive, aqueles que estão diante da câmera (Burgess, Enzle \& Morry, 2000). Dollinger e Clancy (1993) afirmam que o pesquisador passa a ver o self dos participantes através dos olhos deles, melhor do que veria pelos seus próprios olhos. Neste sentido, segundo os autores, uma vantagem do método autofotográfico é que as categorias estão implícitas nas próprias fotos, ao invés de estarem nos itens dos questionários propostos por pesquisadores. Além disso, o método propicia, às pessoas, uma oportunidade de se mostrarem, em diferentes aspectos, através de um instrumento extremamente acessível, a fotografia.

Através deste levantamento histórico-metodológico do uso da fotografia na pesquisa psicológica, foi possível descrever os diferentes métodos adotados, bem como identificar as funções gerais ocupadas pela fotografia nestes trabalhos. Em cada uma das funções, encontrou-se vantagens e desvantagens interligadas às especificidades dos diversos procedimentos. Contudo, observou-se um destaque sobre a prevalência das inúmeras vantagens da utilização do recurso fotográfico, especialmente na aplicação do método autofotográfico, em comparação às possíveis desvantagens apontadas pelos pesquisadores. Em termos concretos, verifica-se a diminuição dos custos nos últimos anos, tanto dos equipamentos, quanto dos materiais utilizados no processamento fotográfico. Face ao exposto, sugere-se a ampliação dos estudos utilizando a fotografia, assim como o conseqüente desenvolvimento do método. A partir dos estudos aqui descritos, justifica-se fortemente a grande contribuição que o uso da fotografia pode fornecer à pesquisa em Psicologia, nas suas diferentes áreas, enfocando os mais variados temas.

\section{Agradecimentos}

Os autores agradecem às alunas Flávia Wagner e Isabela Steigleder Gozalvo (Psicologia - UFRGS) pela prestimosa colaboração na pesquisa bibliográfica e revisão deste manuscrito.

\section{Referências}

Amerikaner, M., Schauble, P., \& Ziller, R. C. (1980). Images: The use of photographs in personal counseling. Personnel and Guidance Journal, 59, 68-73.

Anderson, L. D. (1921). Estimating intelligence by means of printed photographs. Journal of Applied Psychology, 5, 152-156.

Barker, C., Pistrang, N., \& Elliot, R. (1994). Research methods in clinical and counseling psychology. New York: Wiley.

Burguess, M., Enzle, M. E., \& Morry, M. (2000). The social psychological power of photography: Can the image-freezing machine make something of nothing? European Journal of Social Psychology, 30, 613-630.

Cameron, E. H., \& Steele, W. M. (1905). The Poggendorff illusion. Psychological Monographs, 7(1), 83-111. Resumo obtido em 28/06/2001, do Banco de dados PsycINFO.

Clancy, S. M., \& Dollinger, S. J. (1993). Photographic depictions of the self: Gender and age differences in social connectedness. Sex Roles, 29, 477-495.

Combs, J. M., \& Ziller, R. C. (1977). Photographic self-concept of counselees. Journal of Counseling Psychology, 24, 452-455.

Conselho Federal de Psicologia (2000). Resolução no 016/2000, de 20 de dezembro de 2000. Brasília, DF.

Cook, S. W. (1939). The judgment of intelligence from photographs. Journal of Abnormal and Social Psychology, 34, 384-389.

Dinklage, R. I., \& Ziller, R. C. (1989). Explicating cognitive conflict through photo-communication. Journal of Conflict Resolution, 33, 309-317.

Dion, K., Berscheid, E., \& Walster, E. (1972). What is beautiful is good. Journal of Personality and Social Psychology, 3, 285-290.

Dollinger, S. J. (1996). Autophotographic identities of young adults: With special reference to alcohol, athletics, achievement, religion, and work. Journal of Personality Assessment, 67, 384-398.

Dollinger, S. J. (2001). Religious identity: An autophotographic study. The International Journal for the Psychology of Religion, 11, 71-92.

Dollinger, S. J. (no prelo). Physical attractiveness, social connectedness and individuality: An autophotographic study. Journal of Social Psychology.

Dollinger, S. J., \& Clancy, S. M. (1993). Identity, self, and personality: II. Glimpses through the autophotographic eye. Journal of Personality and Social Psychology, 64, 1064-1071.

Dollinger, S. J., Cook, C. A., \& Robinson, N. M. (1999). Correlates of autophotographic individuality: Therapy experience and loneliness. Journal of Social and Clinical Psychology, 18, 325-340.

Dollinger, S. J., \& Dollinger, S. M. C. (1997). Individuality and identity exploration: An autophotographic study. Journal of Research Personality, 31, 337-354.

Dollinger, S. J., Preston, L. A., O’Brien, S. P., \& DiLalla, D. L. (1996). Individuality and relatedness of the self: An autophotographic study.Journal of Personality and Social Psychology, 71, 1268-1278.

Dollinger, S. J., Rhodes, K. A., \& Corcoran, K. J. (1993). Photographically portrayed identities, alcohol expectancies, and excessive drinking. Journal of Personality Assessment, 60, 522-531.

Dollinger, S. J., Robinson, N. M., \& Ross, V. J. (1999). Photographic individuality, breadth of perspective, and creativity. Journal of Personality, 67, 623-644.

Dollinger, S. J., Ross, V. L., \& Preston, L. A. (no prelo). Intellect and individuality. Creativity Research Journal.

Donaldson, H. (1890). Anatomical observations on the brain and several senseorgans of the blind, deaf-mute, Laura Dewey Bridgman. American Journal of Psychology, 3(3), 293-342. Resumo obtido em 28/06/2001, do Banco de dados PsycINFO.

Ekman, P., \& Friesen, W. V. (1971). Constants across cultures in the face and emotion. Journal of Personality and Social Psychology, 17, 124-129.

Evans, E. D., Rutberg, J., Carmela, S., \& Charli, T. (1991). Content analysis of contemporary teen magazines for adolescent females. Youth and Society, 23, 99-120. 
Fryrear, J. L., Nuell, L. R., \& Ridley, S. D. (1974). Photographic self-concept enhancement of male juvenile delinquents. Journal of Consulting and Clinical Psychology, 42, 915.

Fryrear, J. L., Nuell, L. R., \& White, P. (1977). Enhancement of male juvenile delinquents' self-concepts through photographed social interactions. Journal of Clinical Psychology, 33, 833-838.

Gaskill, P. C., Fenton, N., \& Porter, J. P. (1927). Judging the intelligence of boys from their photographs. Journal of Applied Psychology, 11, 393-403.

Gosciewski, F. W. (1975). Photo counseling. Personnel and Guidance Journal, 53, 600-604.

Henry, P. H., \& Solano, C. H. (1983). Photographic style and personality: Developing a coding system for photographs. The Journal of Psychology, $115,79-87$.

Judd, C. H. (1905). The Muller-Lyer illusion. Psychological Monographs, 7(1), 55-81. Resumo obtido em 28/06/2001, do Banco de dados PsycINFO.

Judd, C. H., \& Courten, H. C. (1905). The Zollner illusion. Psychological Monographs, 7(1), 112-139. Resumo obtido em 28/06/2001, do Banco de dados PsycINFO.

Judd, C. H., McAllister, C. N., Cloyd, N., \& Steele, W. M. (1905). General introduction to a series of studies of eye movements by means of kinetoscopic photographs. Psychological Monographs, 7(1), 1-16. Resumo obtido em 28/06/2001, do Banco de dados PsycINFO.

Laird, D. A., \& Remmers, H. (1924). A study of estimates of intelligence from photographs. Journal of Experimental Psychology, 7, 429-446.

Landis, C. (1924). Studies of emotional reactions: I. A preliminary study of facial expression. Journal of Experimental Psychology, 7, 325-341.

Maciel, C., Brito, S., \& Camino, L. (1998). Explicações das desigualdades sociais: Um estudo com meninos em situação de rua de João Pessoa. Psicologia: Reflexão e Crítica, 11, 209-232.

McAlister, C. N. (1905). The fixation of points in the visual field. Psychological Monographs, 7(1), 17-53. Resumo obtido em 28/06/2001, do Banco de dados PsycINFO.

Mills, J. (1984). Self-posed behaviors of females and males in photographs. Sex Roles, 10, 633-637.
Monteiro, J. M. C., \& Dollinger, S. J. (1996). Estudo etnográfico e autofotográfico do menino na rua em Fortaleza, Ceará. Coletâneas da ANPEPP - Associação Nacional de Pesquisa e Pós-Graduação em Psicologia, 1(12), 45-60.

Monteiro, J. M. C., \& Dollinger, S. J. (1998). An autophotographic study of poverty, collective orientation, and identity among street children. The Journal of Social Psychology, 138, 403-406.

Moriwaki, E. (1929). Note on the comparative validities of judgments of intelligence based on photographs and on interviews. Journal of Applied Psychology, 13, 630-631.

Okura, Y., Ziller, R. C., \& Osawa, H. (1985-1986). The psychological niche of older Japanese and Americans through auto-photography: Aging and the search for peace. International Journal of Aging and Human Development, $22,247-259$.

Ortony, A., \& Reynolds, R. E. (1978). Metaphor: Theoretical and empirical research. Psychological Bulletin, 85, 919-943.

Rorer, B., \& Ziller, R. C. (1982). Iconic communication of values among American and Polish students. Journal of Cross-Cultural Psychology, 13, 352-361.

Walther, J. B., Slovacek, C. L., \& Tidwell, L. C. (2001). Is a picture worth a thousand words? Photographic images in long-term and short-term computermediated communication. Communication Research, 28, 105-134.

Ziller, R. C. (1990). Photographing the self. Newbury Park: Sage.

Ziller, R. C. (2001). The meaning of life personality photo-inventory. Acesso em 15/10/2001, no World Wide Web: http://www.psych.ufl.edu/ ziller/

Ziller, R. C., \& Lewis, D. (1981). Orientations: Self, social, and environmental percepts through auto-photography. Personality and Social Psychology Bulletin, 7, 338-343.

Ziller, R. C., \& Rorer, B. A. (1985). Shyness-environment interaction: A view from the shy side through auto-photography. Journal of Personality, 53, 626-639.

Ziller, R. C., \& Smith, D. E. (1977). A phenomenological utilization of photographs. Journal of Phenomenological Psychology, 7, 172-182.

Ziller, R. C., Vern, H., \& de Santoya, C. C. (1988). The psychological niche of children of poverty or affluence through auto-photography. Children's Environments Quarterly, 5, 34-39.

\section{Nota}

1 Este trabalho faz parte dos estudos de Mestrado do primeiro autor, sob orientação da segunda autora, no Programa de Pós-Graduação em Psicologia do Desenvolvimento da Universidade Federal do Rio Grande do Sul, Porto Alegre, RS. Apoio CAPES.

Lucas Neiva-Silva é psicólogo, mestrando em Psicologia do Desenvolvimento da Universidade Federal do Rio Grande do Sul, membro do Centro de Estudos Psicológicos sobre Meninos e Meninas de Rua (CEP-Rua/ UFRGS) e coordenador da Equipe de Pesquisa sobre Expectativas Futuras e Resiliência em Crianças e Adolescentes em Situação de Rua do CEP-Rua/UFRGS.

Sílvia Helena Koller, psicóloga, doutora em Educação, Pesquisadora do CNPq, coordenadora do Centro de Estudos Psicológicos sobre Meninos e Meninas de Rua (CEP-RUA), é professora e orientadora nos Cursos de Graduação e Pós-Graduação em Psicologia do Desenvolvimento da Universidade Federal do Rio Grande do Sul. Presidente da Sociedade Brasileira de Psicologia do Desenvolvimento.

Endereço para correspondência: CEP-RUA, Instituto de Psicologia, Universidade Federal do Rio Grande do Sul. Rua Ramiro Barcelos, 2600, sala 104, 90035-003, Porto Alegre, RS.

Fone: (51)3316.5150, Fax: (51)3330.9507, E-mail: [LNS] lucasneiva@yahoo.com.br; [SHK] kollersh@ufrgs.br. 